\title{
Relationship of microRNA locus with type 2 diabetes mellitus: a case-control study
}

\author{
Qiuyu Huang ${ }^{1,2, *}$, Hanshen Chen ${ }^{3, *}$, Fan Xu ${ }^{1,2}$, Chao Liu ${ }^{4}$, Yafeng Wang ${ }^{5}$, Weifeng Tang ${ }^{6}$ and Liangwan Chen ${ }^{1,2}$ \\ 'Department of Cardiovascular Surgery, Union Hospital, Fujian Medical University, Fuzhou, Fujian Province, China \\ ${ }^{2}$ Key Laboratory of Cardio-Thoracic Surgery (Fujian Medical University), Fujian Province University, Fuzhou, Fujian Province, China \\ ${ }^{3}$ Department of Anesthesiology, The First Affiliated Hospital of Fujian Medical University, Fuzhou, Fujian Province, China \\ ${ }^{4}$ Department of Cardiothoracic Surgery, Affiliated People's Hospital of Jiangsu University, Zhenjiang, Jiangsu Province, China \\ ${ }^{5}$ Department of Cardiology, The People's Hospital of Xishuangbanna Dai Autonomous Prefecture, Jinghong, Yunnan Province, China \\ ${ }^{6}$ Department of Cardiothoracic Surgery, Nanjing Drum Tower Hospital, Nanjing University Medical School, Jiangsu Province, China
}

Correspondence should be addressed to W Tang or L Chen: twf001001@126.com or chenliangwan@tom.com

*(Q Huang and $\mathrm{H}$ Chen contributed equally to this work)

\begin{abstract}
Type 2 diabetes mellitus (T2DM) is considered as a metabolic disease with hyperglycemia. Accumulating investigations have explored the important role of hereditary factors for T2DM occurrence. Some functional microRNA (miR) polymorphisms may affect their interactions with target mRNAs and result in an aberrant expression. Thus, miR variants might be considered as a biomarker of the susceptibility of T2DM. In this study, we recruited 502 T2DM cases and 782 healthy subjects. We selected miR-146a rs2910164 C>G, miR-196a2 rs11614913 T>C and miR-499 rs3746444 A>G loci and carried out an investigation to identify whether these miR loci could influence T2DM occurrence. In this investigation, a Bonferroni correction was harnessed. After adjustment, we found that rs2910164 SNP was a protective factor for T2DM (GG vs CC/CG: adjusted $P=0.010$ ), especially in never drinking (GG vs CC/CG: adjusted $P=0.001$ ) and BMI $\geq 24 \mathrm{~kg} / \mathrm{m}^{2}$ (GG vs CC/CG: adjusted $P=0.002$ ) subgroups. We also identified that rs11614913 SNP was a protective factor for T2DM in smoking subjects (CC/TC vs TT: adjusted $P=0.002$ ). When we analyzed an interaction of SNP-SNP with the susceptibility tof T2DM, rs11614913/ rs3746444, rs2910164/rs3746444 and rs11614913/rs2910164 combinations were not associated with the risk of T2DM. In summary, this study highlights that rs2910164 SNP decreases the susceptibility of T2DM, especially in BMI $\geq 24 \mathrm{~kg} / \mathrm{m}^{2}$ and never drinking subgroups. In addition, we also identify that rs11614913 C allele decreases the susceptibility of T2DM significantly in smoking subgroup.
\end{abstract}

Key Words

- polymorphism

- type 2 diabetes mellitus

risk

- microRNA

\section{Introduction}

Type 2 diabetes mellitus (T2DM) is considered as a metabolic disease with hyperglycemia and vascular and/or nervous complications. In China, the reported prevalence of T2DM is $11.6 \%$ (1), which appears to have increased in the past decades (2). Latest investigation suggested that healthy lifestyle in terms of reasonably restricted calorie intake and adequate physical exercise was associated with lower incidence rate and older age of onset in T2DM (3). However, the etiology of T2DM was not fully understood. The important risk factors, calorie abundant diet, inadequate physical activities, overweight and obesity, may lead to this phenomenon $(4,5)$. Recently, some investigations also suggested genetic components could be implicated in development of T2DM $(3,6)$. Accumulating case-control studies have focused on the important role of hereditary factors in the occurrence of T2DM, and individual's genotype variants deserve a close look.

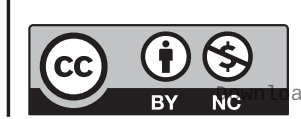

This work is licensed under a Creative Commons Attribution-NonCommercial 4.0 International License. ded from Bioscientifica.com at 04/26/2023 01:20:06PM 
MicroRNA (miR) is a kind of non-coding RNA, which is composed of about 22 nucleotides $(7,8)$. On the posttranslational process, miRs could regulate the expression of target genes (9). miRs are involved in a lot of complex diseases, such as T2DM, which seem to play a role in the development of inflammation (10), fat deposition (11), pancreatic $\beta$-cell apoptosis (12) and so on. In addition, more and more studies focused on functional importance of miRs in the process of proliferation of smooth muscle cells, oxidative stress and energy metabolism (13, 14, $15,16,17,18)$, which are correlated with T2DM and its complications.

SNPs are located at pre-miR genes. Some functional miR-SNPs may affect the interaction with mRNA of their target genes and result in an aberrant expression (19). Thus, miR-SNP might be considered as a useful biomarker of the susceptibility of T2DM. A previous study suggested that $m i R-146 a$ influenced the development of cancer cell by facilitating migration and invasion (20), while miR-146a rs2910164 C>G SNP could promote the expression of $m i R-146 a$ and results in immune suppression $(21,22,23)$. Liu et al. reported that mimics of $m i R-146 a$ could decrease the peripheral neuropathy of T2DM mice (24). This miR-146a SNP might be implicated in the susceptibility and development of T2DM. There are several studies on the correlation of rs2910164 SNP with risk of T2DM (25, $26,27,28)$. Recently, a meta-analysis has suggested that rs2910164 G allele might be associated with risk of T2DM. However, only 4 case-control studies with 2069 cases and 1950 controls were included (29), and the observations might be underpowered. Additionally, the relationship of miR-196a2 rs11614913 T>C and miR-499 rs3746444 $\mathrm{A}>\mathrm{G}$ SNPs with the risk of T2DM was also explored. The included participants were more limited, and the findings were more conflicting. In 2020, Gholami et al. systematically reviewed the SNPs associated with T2DM (30). In view of the potential effect of miR-SNPs in the occurrence of T2DM, we selected rs11614913, rs2910164 and rs3746444 loci and carried out an investigation to identify whether these miR-SNPs could influence the risk of T2DM.

\section{Materials and methods}

\section{Study population and ethical approval}

In this study, 502 T2DM cases who had presented to the Zhenjiang No. 1 hospital (Zhenjiang City, China) and Union Hospital of Fujian province (Fuzhou City, China) between October 2014 and May 2016 consecutively were recruited. And at the same time, 782 healthy subjects were enrolled as controls. Consent has been obtained from each patient or subject after full explanation of the purpose and nature of all procedures used. The criterion of the included T2DM patients was diagnosed according to the criterion of WHO 1999 guidelines (31). The criteria of healthy subjects were (1) normoglycemia (fasting plasma glucose (FPG) $<6.1 \mathrm{mmol} / \mathrm{L}$ ), (2) postprandial plasma glucose $<7.8$ $\mathrm{mmol} / \mathrm{L}$ and (3) no history of diabetes mellitus (32). Two authors visited each subject and collected risk factors and demographic variables. We summarized the information in Table 1. Weight, height and blood pressure were measured. In Chinese adults, a BMI $\geq 24 \mathrm{~kg} / \mathrm{m}^{2}$ was regarded as the criterion for overweight and obesity $(33,34)$. Serum HDL-C, FPG, total cholesterol, LDL-C and triglycerides were measured. The protocol was approved by Committee of Ethics at Fujian Medical University.

\section{SNP selection}

To determine the potential relationship between miR-SNPs and T2DM, we selected the miR-146a rs2910164 C>G, miR-196a2 rs11614913 T>C and miR-499 rs3746444 A $>$ G loci polymorphism according to the literature, which was significantly associated with cancer $(20,21,22,23)$, coronary artery disease $(35,36)$ and type 2 diabetes $(25,26$, $27,28,30)$, in some studies.

\section{DNA extraction and genotyping}

EDTA anticoagulant vacutainer tube (BD, Franklin Lakes NJ, USA) was used to collect the blood sample. Genomic DNA was extracted by using the DNA Purification Kit (Promega). SNPscan ${ }^{\mathrm{TM}}$ genotyping assay was carried out to identify the genotypes of rs3746444, rs11614913 and rs2910164. As summarized in Table 2, more than 99\% sample was successfully genotyped. The genotypes of rs3746444, rs11614913 and rs2910164 SNP were confirmed with DNA sequence method in 4\% DNA samples randomly.

\section{Statistical analysis}

SAS 9.4 software (SAS Institute, Cary, NC, USA) was harnessed to perform statistical analyses. Mean \pm S.D. was used to express continuous variables. The difference of continuous variables between two groups was measured by Student's $t$ test. The differencces categorical variables (smoking status, alcohol consumption, BMI, genotypes, sex and age) were measured using chi-square test $\left(\chi^{2}\right)$. Using the genotype number in controls of rs3746444, rs11614913 and rs2910164, Hardy-Weinberg equilibrium (HWE) 
Table 1 Distribution of selected demographic variables and risk factors in T2DM cases and controls.

\begin{tabular}{l}
\hline Variable \\
\hline Age (years) \\
Age (years) \\
$<65$ \\
$\geq 65$ \\
Sex \\
Male \\
Female \\
Alcohol use \\
Never \\
Ever \\
Smoking status \\
Never \\
Ever \\
Height (m) \\
Weight $(\mathrm{kg})$ \\
BMI $\left(\mathrm{kg} / \mathrm{m}^{2}\right)$ \\
BMI $\left(\mathrm{kg} / \mathrm{m}^{2}\right)$ \\
$<24$ \\
$\geq 24$ \\
FPG (mmol/L) \\
Total cholesterol $(\mathrm{mmol} / \mathrm{L})$ \\
Triglyceride $(\mathrm{mmol} / \mathrm{L})$ \\
HDL-C (mmol/L) \\
LDL-C (mmol/L) \\
Systolic pressure $(\mathrm{mmHg})$ \\
Diastolic pressure $(\mathrm{mmHg})$ \\
\hline
\end{tabular}

\begin{tabular}{c}
\hline Cases $(n=502)$ \\
\hline$n$
\end{tabular}

$65.20( \pm 9.51)$

$\begin{array}{cr}227 & 45.22 \\ 275 & 54.78 \\ 332 & 66.14 \\ 170 & 33.86 \\ & \\ 453 & 90.24 \\ 49 & 9.76 \\ & \\ 333 & 66.33 \\ 169 & 33.67 \\ 1.68( \pm 0.08) & \\ 67.63( \pm 11.42) & \\ 24.95( \pm 3.64) & \\ & \\ 210 & \\ 292 & \\ 8.08( \pm 2.76) & \\ 4.61( \pm 1.24) & \\ 1.74( \pm 1.14) & \\ 1.13( \pm 0.37) & \\ 3.00( \pm 1.07) & \\ 135( \pm 18) & \\ 80( \pm 10) & \end{array}$

aTwo-sided $\chi^{2}$ test and Student's $t$ test; bold values are statistically significant $(P<0.05)$. FPG, fasting plasma glucose.

was evaluated by an internet-based calculator $(37,38,39$, $40,41)$. The correlations of rs3746444, rs11614913 and rs2910164 polymorphisms with occurrence of T2DM were determined by odds ratios (ORs) and CIs. A $P<0.05$ (twotailed) was regarded as the statistical significance. In this case-control study, a Bonferroni correction was harnessed to confirm our findings $(42,43)$.

\section{Results}

\section{Baseline characteristics}

Table 1 summarizes the demographics and risk factors, anthropometric data, biochemistry characteristics. Gender, age, smoking status and alcohol consumption were well matched. Compared with controls, the mean level of BMI was higher in the T2DM group $(P<0.05)$. In this study, the mean level of diastolic pressure and systolic pressure was similar. Other information, HDL-C, FPG, total cholesterol, LDL-C and triglycerides, were also summarized in Table 1 . Table 2 shows the primary SNPs information of rs3746444, rs11614913 and rs2910164. Minor allele frequency is summarized in Table 2.

\begin{tabular}{|c|c|c|}
\hline \multicolumn{2}{|c|}{ Controls $(n=782)$} & \multirow[b]{2}{*}{$p^{a}$} \\
\hline$n$ & $\%$ & \\
\hline \multirow{2}{*}{\multicolumn{2}{|c|}{$64.67( \pm 9.80)$}} & 0.347 \\
\hline & & 0.113 \\
\hline 389 & 49.74 & \\
\hline \multirow[t]{2}{*}{393} & 50.26 & \\
\hline & & 0.819 \\
\hline 522 & 66.75 & \\
\hline \multirow[t]{2}{*}{260} & 33.25 & \\
\hline & & 0.263 \\
\hline 690 & 88.24 & \\
\hline \multirow[t]{2}{*}{92} & 11.76 & \\
\hline & & 0.264 \\
\hline 542 & 69.31 & \\
\hline 240 & 30.69 & \\
\hline $1.66( \pm 0.07)$ & & 0.015 \\
\hline $64.62( \pm 9.96)$ & & $<0.001$ \\
\hline \multirow[t]{2}{*}{$23.51( \pm 2.94)$} & & $<0.001$ \\
\hline & & $<0.001$ \\
\hline \multicolumn{3}{|l|}{436} \\
\hline \multicolumn{3}{|l|}{346} \\
\hline $5.13( \pm 0.49)$ & & $<0.001$ \\
\hline $4.88( \pm 1.02)$ & & $<0.001$ \\
\hline $1.55( \pm 0.96)$ & & 0.001 \\
\hline $1.30( \pm 0.37)$ & & $<0.001$ \\
\hline $3.14( \pm 0.82)$ & & 0.010 \\
\hline $134( \pm 18)$ & & 0.297 \\
\hline $80( \pm 10)$ & & 0.649 \\
\hline
\end{tabular}

\section{Association of rs3746444, rs11614913 and rs2910164 loci with T2DM}

The rs3746444, rs11614913 and rs2910164 genotype distributions are shown in Table 3 . The distributions of the rs3746444 and rs2910164 genotypes were suggested to be in HWE. In an analysis of miR-146a rs2910164 SNP, compared with miR-146a rs2910164 CC or CC/CG genotype, the frequency distribution of $m i R-146 a$ rs2910164 GG genotype was different between healthy controls and T2DM cases (GG vs CC: crude $P=0.046$ and GG vs CG/CC: crude $P=0.006)$. After a logistic regression analysis, it is also suggested that $m i R-146 a$ rs2910164 SNP decreased the susceptibility of T2DM (GG vs CC: adjusted $P=0.036$ and GG vs CG/CC: adjusted $P=0.004)$. However, miR-196a2 rs11614913 and miR-499 rs3746444 SNPs were not correlated with the occurrence of T2DM.

\section{Subgroup analysis of the association of miR-SNPs with T2DM}

$m i R-196 a 2$ rs11614913 genotypes in the stratified analysis are shown in Table 4 . The subgroup analysis was conducted according to the included risk factors. In $\geq 65$ years

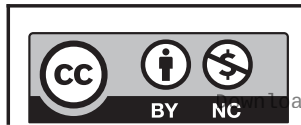

This work is licensed under a Creative Commons Attribution-NonCommercial 4.0 International License. ded from Bioscientifica.com at 04/26/2023 01:20:06PM via free access 
Table 2 Primary information for miR-146a rs2910164 C>G, miR-196a2 rs11614913 T>C and miR-499 rs3746444 A>G polymorphisms.

\begin{tabular}{lll}
\hline Genotyped SNPs & & miR-146a rs2910164 C>G \\
\cline { 1 - 1 } Chromosome & 5 & nc-transcript-variant \\
Function & 160485411 \\
Chr Pos (NCBI Build 38) & 0.35 \\
MAF for Chinese in database & 0.38 \\
MAF in our controls $(n=1109)$ & 0.119 \\
$P$ value for HWE test in our controls & SNPscan \\
Genotyping method & $99.61 \%$ \\
\% Genotyping value &
\end{tabular}

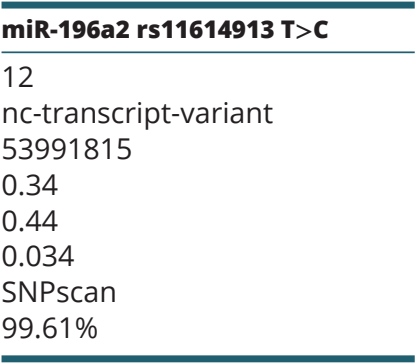

\begin{tabular}{l} 
miR-499 $\mathbf{r s 3 7 4 6 4 4 4} \mathbf{A}>\mathbf{G}$ \\
\hline 20 \\
nc-transcript-variant \\
3499048 \\
0.15 \\
0.15 \\
0.702 \\
SNPscan \\
$99.61 \%$
\end{tabular}

HWE, Hardy-Weinberg equilibrium; MAF, minor allele frequency.

subgroup, after adjustment for smoking status, gender, alcohol use and BMI, rs11614913 TC and CC/TC genotypes might decrease T2DM susceptibility compared with rs11614913 TT genotype (TC vs TT: adjusted $P=0.013$ and CC/TC vs TT: adjusted $P=0.011$ ). Compared with rs 11614913 TT genotype, rs11614913 TC, CC and CC/TC genotypes decreased the susceptibility of T2DM significantly in smoking subgroup (TC vs TT: adjusted $P=0.005$, CC vs TT: adjusted $P=0.018$ and CC/TC vs TT: adjusted $P=0.002$ ). In drinking subgroup, compared with rs11614913 TT genotype, rs11614913 TC and CC/TC genotypes decreased the susceptibility of T2DM significantly (TC vs TT: adjusted
$P=0.007$ and $\mathrm{CC} / \mathrm{TC}$ vs TT: adjusted $P=0.020)$. In BMI $<24$ $\mathrm{kg} / \mathrm{m}^{2}$ subgroup, compared with rs11614913 TT genotype, rs11614913 CC and CC/TC genotypes decreased the susceptibility of T2DM significantly (CC vs TT: adjusted $P=0.013$ and CC/TC vs TT: adjusted $P=0.030$ ).

In the stratified analysis, miR-146a rs2910164 genotypes are shown in Table 5. In female subgroup, compared with rs2910164 CC and CC/CG genotypes, rs2910164 GG genotypes might decrease T2DM susceptibility (GG vs CC: adjusted $P=0.019$ and GG vs CC/CG: adjusted $P=0.010$ ). In $\geq 65$ years subgroup, rs2910164 GG genotypes might decrease T2DM

Table 3 The relationship of miRNA polymorphisms with T2DM.

\begin{tabular}{|c|c|c|c|c|}
\hline \multirow[b]{2}{*}{ Genotype } & \multicolumn{2}{|c|}{ Cases $(n=502)$} & \multicolumn{2}{|c|}{ Controls $(n=782)$} \\
\hline & $n$ & $\%$ & $n$ & $\%$ \\
\hline \multicolumn{5}{|c|}{ miR-499 rs3746444 } \\
\hline AA & 363 & 73.04 & 565 & 72.25 \\
\hline$A G$ & 125 & 25.15 & 201 & 25.70 \\
\hline GG & 9 & 1.81 & 16 & 2.05 \\
\hline$A G+G G$ & 134 & 26.96 & 217 & 27.75 \\
\hline$A A+A G$ & 488 & 98.19 & 766 & 97.95 \\
\hline GG & 9 & 1.81 & 16 & 2.05 \\
\hline G allele & 143 & 14.39 & 233 & 14.90 \\
\hline \multicolumn{5}{|c|}{ miR-146a rs2910164 } \\
\hline $\mathrm{CC}$ & 187 & 37.63 & 308 & 39.39 \\
\hline CG & 258 & 51.91 & 349 & 44.63 \\
\hline GG & 52 & 10.46 & 125 & 15.98 \\
\hline $\mathrm{CG}+\mathrm{GG}$ & 310 & 62.37 & 474 & 60.61 \\
\hline $\mathrm{CC}+\mathrm{CG}$ & 445 & 89.54 & 657 & 84.01 \\
\hline GG & 52 & 10.46 & 125 & 15.98 \\
\hline G allele & 362 & 36.42 & 599 & 38.30 \\
\hline \multicolumn{5}{|c|}{ miR-196a2 rs11614913 } \\
\hline TT & 165 & 33.20 & 229 & 29.28 \\
\hline $\mathrm{TC}$ & 251 & 50.50 & 415 & 53.07 \\
\hline $\mathrm{CC}$ & 81 & 16.30 & 138 & 17.65 \\
\hline $\mathrm{TC}+\mathrm{CC}$ & 332 & 66.80 & 553 & 70.72 \\
\hline $\mathrm{TT}+\mathrm{TC}$ & 416 & 83.70 & 644 & 82.35 \\
\hline$C C$ & 81 & 16.30 & 138 & 17.65 \\
\hline C allele & 413 & 41.55 & 691 & 44.18 \\
\hline
\end{tabular}

\begin{tabular}{|c|c|c|c|}
\hline Crude OR $(95 \% \mathrm{Cl})$ & $\boldsymbol{P}$ & Adjusted OR $\mathbf{a}^{\mathbf{a}}(95 \% \mathrm{Cl})$ & $P$ \\
\hline 1.00 & & 1.00 & \\
\hline $0.97(0.75-1.25)$ & 0.806 & $0.95(0.73-1.23)$ & 0.689 \\
\hline $0.88(0.38-2.00)$ & 0.753 & $0.89(0.39-2.06)$ & 0.788 \\
\hline $0.96(0.75-1.24)$ & 0.759 & $0.94(0.73-1.22)$ & 0.657 \\
\hline 1.00 & & 1.00 & \\
\hline $0.88(0.39-2.01)$ & 0.767 & $0.90(0.39-2.08)$ & 0.813 \\
\hline 1.00 & & 1.00 & \\
\hline $1.22(0.96-1.55)$ & 0.112 & $1.22(0.96-1.56)$ & 0.110 \\
\hline $0.69(0.47-0.99)$ & 0.046 & $0.67(0.46-0.97)$ & 0.036 \\
\hline $1.07(0.86-1.36)$ & 0.530 & $1.07(0.85-1.36)$ & 0.548 \\
\hline 1.00 & & 1.00 & \\
\hline $0.61(0.44-0.87)$ & 0.006 & $0.60(0.42-0.85)$ & 0.004 \\
\hline 1.00 & & 1.00 & \\
\hline $0.84(0.65-1.08)$ & 0.177 & $0.83(0.64-1.07)$ & 0.151 \\
\hline $0.82(0.58-1.14)$ & 0.237 & $0.83(0.59-1.18)$ & 0.301 \\
\hline $0.83(0.65-1.06)$ & 0.140 & $0.83(0.65-1.06)$ & 0.135 \\
\hline 1.00 & & 1.00 & \\
\hline $0.91(0.67-1.23)$ & 0.533 & $0.94(0.69-1.27)$ & 0.682 \\
\hline
\end{tabular}

Bold values are statistically significant $(P<0.05)$.

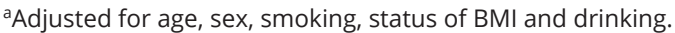

https://ec.bioscientifica.com

https://doi.org/10.1530/EC-21-0261 (c) 2021 The authors Published by Bioscientifica Ltd

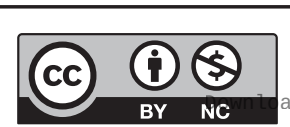

This work is licensed under a Creative Commons Attribution-NonCommercial 4.0 International License. ded from Bioscientifica.com at 04/26/2023 01:20:06PM via free access 


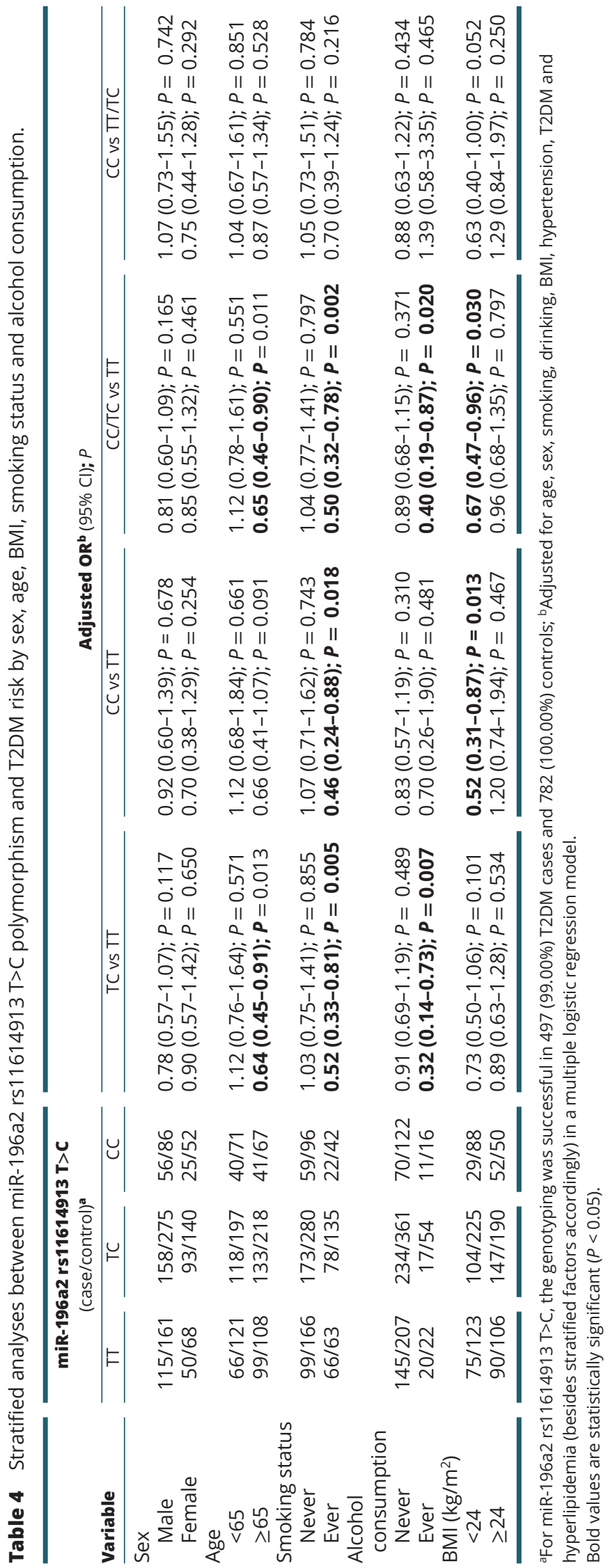

https://ec.bioscientifica.com https://doi.org/10.1530/EC-21-0261

(c) 2021 The authors Published by Bioscientifica Ltd susceptibility compared with rs2910164 CC and CC/CG (GG vs CC: adjusted $P=0.049$ and GG vs CC/CG: adjusted $P=0.020$ ). Compared with rs2910164 CC and CC/CG genotypes, rs2910164 GG genotypes decreased the susceptibility of T2DM significantly in individuals 7,without tobacco consumption (GG vs CC: adjusted $P=0.024$ and GG vs CC/CG: adjusted $P=0.004)$. In nondrinking subgroup, compared with rs2910164 CC and CC/CG genotypes, rs2910164 GG genotype decreased the susceptibility of T2DM significantly (GG vs CC: adjusted $P=0.014$ and GG vs CC/CG: adjusted $P=0.001)$. In obesity/ overweight subgroup, compared with rs2910164 CC and CC/CG genotypes, rs2910164 GG genotype decreased the susceptibility of T2DM significantly (GG vs CC: adjusted $P=0.045$ and GG vs CC/CG: adjusted $P=0.002$ ). However, compared with rs2910164 CC genotype, rs2910164 CG genotype might increase the susceptibility of T2DM significantly in obesity/overweight subgroup (CG vs CC: adjusted $P=0.028$ ).

When we focused on the association of the miR-499 rs3746444 SNP with the risk of T2DM, null association was found (Table 6).

\section{Bonferroni correction}

A Bonferroni correction was harnessed to confirm our findings in this study. After adjustment, we found that $m i R-146 a$ rs2910164 SNP was a protective factor for T2DM, especially in non-drinking and $\mathrm{BMI} \geq 24 \mathrm{~kg} / \mathrm{m}^{2}$ subgroups. We also identified that miR-196a2 rs11614913 SNP was a protective factor for T2DM in smoking subjects.

\section{Combination analysis of miRNA polymorphisms}

miR-SNPs combined analyses were summarized in Table 7. When we analyzed the interactions of SNP-SNP with the susceptibility of T2DM, rs11614913/rs3746444, rs2910164/rs3746444, rs11614913/rs2910164 and rs11614913/rs2910164/rs3746444 combinations were used. However, null association was found.

\section{Power calculation}

Using $\alpha=0.05$ as the criterion of the Type I error probability (two-sided), we calculated the power value of this study. For miR-146a rs2910164 SNP, the power value was 0.838 in overall comparison, 0.916 in non-drinker subgroup and 0.877 in $B M I \geq 24 \mathrm{~kg} / \mathrm{m}^{2}$ subgroup among the GG vs CG/CC genetic model. For miR-196a2 rs11614913 SNP, the power value was 0.898 in drinker subgroup among the

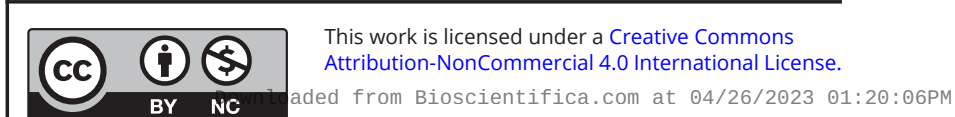



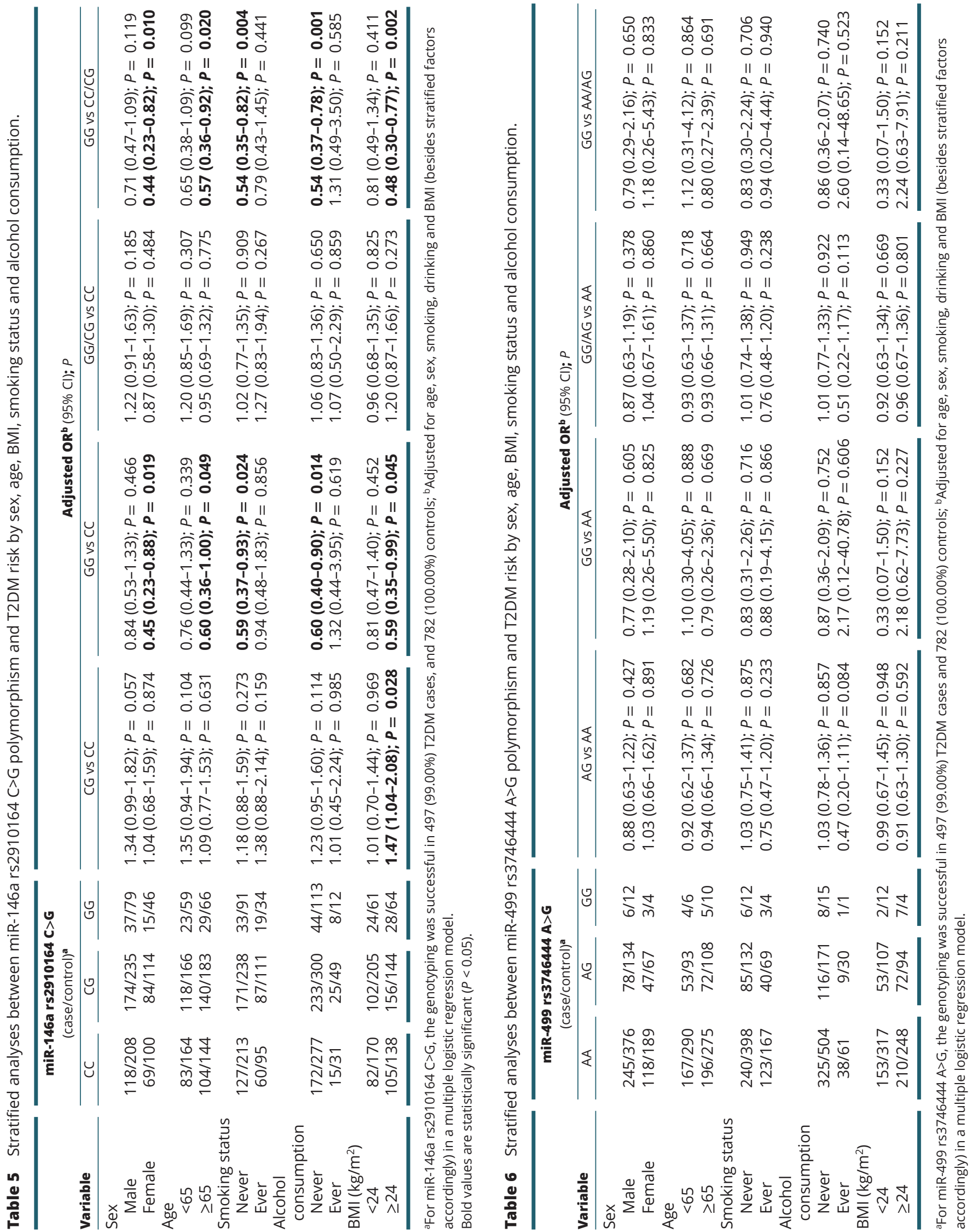
Table 7 Combination analysis of miRNA loci (rs3746444, rs2910164 and rs11614913) in T2DM cases and controls.

\begin{tabular}{|c|c|c|c|c|c|c|}
\hline \multirow[b]{2}{*}{ Genotype } & \multicolumn{2}{|c|}{ Case } & \multicolumn{2}{|c|}{ Control } & \multirow[b]{2}{*}{ OR $(95 \% \mathrm{Cl})$} & \multirow[b]{2}{*}{$P$ value } \\
\hline & $n$ & $\%$ & $n$ & $\%$ & & \\
\hline \multicolumn{7}{|c|}{ rs11614913/rs2910164 } \\
\hline TT/CC & 51 & 10.26 & 87 & 11.13 & 1.00 & \\
\hline TT/CG & 93 & 18.71 & 106 & 13.55 & $1.50(0.96-2.33)$ & 0.074 \\
\hline TT/GG & 21 & 4.23 & 36 & 4.60 & $1.00(0.52-1.89)$ & 0.988 \\
\hline $\mathrm{TC} / \mathrm{CC}$ & 105 & 21.13 & 165 & 21.10 & $1.09(0.71-1.66)$ & 0.704 \\
\hline $\mathrm{TC} / \mathrm{CG}$ & 125 & 25.15 & 185 & 23.66 & $1.15(0.76-1.74)$ & 0.501 \\
\hline $\mathrm{TC} / \mathrm{GG}$ & 21 & 4.23 & 65 & 8.31 & $0.55(0.30-1.01)$ & 0.051 \\
\hline $\mathrm{CC} / \mathrm{CC}$ & 31 & 6.24 & 56 & 7.16 & $0.94(0.54-1.65)$ & 0.841 \\
\hline $\mathrm{CC} / \mathrm{CG}$ & 40 & 8.05 & 58 & 7.42 & $1.18(0.69-2.00)$ & 0.548 \\
\hline $\mathrm{CC} / \mathrm{GG}$ & 10 & 2.01 & 24 & 3.07 & $0.71(0.31-1.61)$ & 0.410 \\
\hline \multicolumn{7}{|c|}{ rs11614913/rs3746444 } \\
\hline TT/AA & 119 & 23.94 & 159 & 20.33 & 1.00 & \\
\hline TT/AG & 43 & 8.65 & 67 & 8.57 & $0.86(0.55-1.35)$ & 0.504 \\
\hline TT/GG & 3 & 0.60 & 3 & 0.38 & $1.34(0.26-6.74)$ & 1.000 \\
\hline TC/AA & 189 & 38.03 & 307 & 39.26 & $0.82(0.61-1.11)$ & 0.200 \\
\hline TC/AG & 57 & 11.47 & 98 & 12.53 & $0.78(0.52-1.16)$ & 0.221 \\
\hline $\mathrm{TC} / \mathrm{GG}$ & 5 & 1.01 & 10 & 1.28 & $0.67(0.22-2.01)$ & 0.470 \\
\hline CC/AA & 55 & 11.07 & 99 & 12.66 & $0.74(0.49-1.11)$ & 0.150 \\
\hline CC/AG & 25 & 5.03 & 36 & 4.60 & $0.93(0.53-1.63)$ & 0.794 \\
\hline CC/GG & 1 & 0.20 & 3 & 0.38 & $0.45(0.05-4.34)$ & 0.639 \\
\hline \multicolumn{7}{|c|}{ rs2910164/rs3746444 } \\
\hline CC/AA & 133 & 26.76 & 220 & 28.13 & 1.00 & \\
\hline CC/AG & 48 & 9.66 & 82 & 10.49 & $0.97(0.64-1.47)$ & 0.879 \\
\hline CC/GG & 6 & 1.21 & 6 & 0.77 & $1.65(0.52-5.24)$ & 0.387 \\
\hline CG/AA & 190 & 38.23 & 247 & 31.59 & $1.27(0.96-1.69)$ & 0.099 \\
\hline CG/AG & 65 & 13.08 & 98 & 12.53 & $1.10(0.75-1.60)$ & 0.633 \\
\hline $\mathrm{CG} / \mathrm{GG}$ & 3 & 0.60 & 4 & 0.51 & $1.24(0.27-5.63)$ & 1.000 \\
\hline GG/AA & 40 & 8.05 & 98 & 12.53 & $0.68(0.44-1.03)$ & 0.070 \\
\hline GG/AG & 12 & 2.41 & 21 & 2.69 & $0.95(0.45-1.98)$ & 0.882 \\
\hline GG/GG & 0 & 0.00 & 6 & 0.77 & $0.13(0.01-2.28)$ & 0.089 \\
\hline \multicolumn{7}{|c|}{ rs11614913/rs2910164/rs3746444 } \\
\hline TT/CC/AA & 35 & 7.04 & 58 & 7.42 & 1.00 & \\
\hline TT/CC/AG & 14 & 2.82 & 29 & 3.71 & $0.80(0.37-1.72)$ & 0.566 \\
\hline TT/CC/GG & 2 & 0.40 & 0 & 0.00 & $8.24(0.38-176.72)$ & 0.149 \\
\hline TT/CG/AA & 70 & 14.08 & 76 & 9.72 & $1.53(0.90-2.59)$ & 0.117 \\
\hline TT/CG/AG & 22 & 4.43 & 29 & 3.71 & $1.26(0.63-2.52)$ & 0.518 \\
\hline TT/CG/GG & 1 & 0.20 & 1 & 0.13 & $1.65(0.10-27.36)$ & 1.000 \\
\hline TT/GG/AA & 14 & 2.82 & 25 & 3.20 & $0.93(0.43-2.02)$ & 0.851 \\
\hline $\mathrm{TT} / \mathrm{GG} / \mathrm{AG}$ & 7 & 1.41 & 9 & 1.15 & $1.29(0.44-3.77)$ & 0.642 \\
\hline TT/GG/GG & 0 & 0.00 & 2 & 0.26 & $0.33(0.02-7.07)$ & 0.530 \\
\hline TC/CC/AA & 78 & 15.69 & 125 & 15.98 & $1.03(0.62-1.72)$ & 0.897 \\
\hline TC/CC/AG & 24 & 4.83 & 36 & 4.60 & $1.10(0.57-2.15)$ & 0.769 \\
\hline TC/CC/GG & 3 & 0.60 & 4 & 0.51 & $1.24(0.26-5.89)$ & 1.000 \\
\hline TC/CG/AA & 93 & 18.71 & 128 & 16.37 & $1.20(0.73-1.98)$ & 0.464 \\
\hline $\mathrm{TC} / \mathrm{CG} / \mathrm{AG}$ & 30 & 6.04 & 55 & 7.03 & $0.90(0.49-1.67)$ & 0.746 \\
\hline $\mathrm{TC} / \mathrm{CG} / \mathrm{GG}$ & 2 & 0.40 & 2 & 0.26 & $1.66(0.22-12.30)$ & 0.635 \\
\hline TC/GG/AA & 18 & 3.62 & 54 & 6.91 & 0.55 (0.28-1.09) & 0.085 \\
\hline TC/GG/AG & 3 & 0.60 & 7 & 0.90 & $0.71(0.17-2.93)$ & 0.742 \\
\hline TC/GG/GG & 0 & 0.00 & 4 & 0.51 & $0.18(0.01-3.51)$ & 0.293 \\
\hline CC/CC/AA & 20 & 4.02 & 37 & 4.73 & $0.90(0.45-1.78)$ & 0.753 \\
\hline $\mathrm{CC} / \mathrm{CC} / \mathrm{AG}$ & 10 & 2.01 & 17 & 2.17 & $0.97(0.40-2.37)$ & 0.955 \\
\hline $\mathrm{CC} / \mathrm{CC} / \mathrm{GG}$ & 1 & 0.20 & 2 & 0.26 & $0.83(0.07-9.48)$ & 1.000 \\
\hline CC/CG/AA & 27 & 5.43 & 43 & 5.50 & $1.04(0.55-1.97)$ & 0.903 \\
\hline CC/CG/AG & 13 & 2.62 & 14 & 1.79 & $1.54(0.65-3.65)$ & 0.326 \\
\hline $\mathrm{CC} / \mathrm{CG} / \mathrm{GG}$ & 0 & 0.00 & 1 & 0.13 & $0.55(0.02-13.86)$ & 1.000 \\
\hline CC/GG/AA & 8 & 1.61 & 19 & 2.43 & $0.70(0.28-1.76)$ & 0.445 \\
\hline CC/GG/AG & 2 & 0.40 & 5 & 0.64 & $0.66(0.12-3.60)$ & 1.000 \\
\hline CC/GG/GG & 0 & 0.00 & 0 & 0.00 & - & - \\
\hline
\end{tabular}

https://ec.bioscientifica.com

https://doi.org/10.1530/EC-21-0261 (c) 2021 The authors Published by Bioscientifica Ltd 
dominant genetic model. These findings suggested that $m i R-146 a$ rs2910164 and miR-196a2 rs11614913 SNPs could be protective factors of T2DM occurrence.

\section{Discussion}

Some investigations have found rs11614913, rs2910164 and rs3746444 loci of miR-SNPs may be potential biomarker for increased incidence of T2DM. However, relationship of the mentioned miR-SNPs with development of T2DM was unclear. This case-control study showed that rs2910164 SNP is associated with decreased susceptibility of T2DM, especially in non-drinking and $\mathrm{BMI} \geq 24 \mathrm{~kg} / \mathrm{m}^{2}$ subgroups. In addition, we also found that rs11614913 C allele may be associated with decreased susceptibility of T2DM significantly in smoking subgroup.

Annexin A1 (ANXA1) is found to be an important antiinflammatory factor. Purvis et al. have reported that ANXA1 level significantly increased in people with hyperglycemia (44). In addition, ANXA1 might be a protective factor for T2DM (45) and imply a new treatment strategy for T2DM (44). Huang et al. have reported that peptide Ac2-26, an ANXA1 N-terminal peptide, promotes wound healing in diabetes (46). Thus, it is suggested that ANXA1 may be implicated in the development of T2DM. A recent study has suggested that miR-196a2 regulates the role of ANXA1(47). rs11614913 $\mathrm{T} \rightarrow \mathrm{C}$ variant in miR-196a2 gene locates at the $3 p$ regions in mature $m i R$ (48). Several investigations found that rs11614913 C allele increased the expression of miR-196a2 (49, 50). Ghanbari et al. have found that rs11614913 C allele decreases waist to hip ratio (51). A previous pooled analysis suggested that rs $11614913 \mathrm{C}$ allele did not influence the susceptibility of T2DM in China (30). However, in this study, we found that rs11614913 C allele decreased the susceptibility of T2DM in smoking subgroup, which might indicate that the role of rs11614913 C allele could be affected by environmental factor. Yin et al. also suggested that an interaction of the rs11614913 genotypes in miR-196a2 gene with environmental factor is associated with an increased susceptibility of lung cancer (52). It might be explained that the correlation of rs11614913 locus with an occurrence of T2DM could be affected by risk factors of environment. Considering a single locus of $m i R$ could only make low penetrance effects on T2DM, the interaction of gene-environment factors may dilute the role of rs11614913, and more investigations are needed to support our findings in the future.

Considering that an individual SNP contributes little to the susceptibility of T2DM, the current investigation urges a need of sufficient power to get an assessment of rs2910164 with T2DM risk. Recently, the correlation of rs2910164 with T2DM risk was explored by several casecontrol studies. A meta-analysis suggested an association of rs2910164 in miR-146a gene with T2DM risk (29). However, in that meta-analysis, only 2069 cases and 1950 controls were included. The observations may be underpowered. Wang et al. suggested that G allele of rs2910164 SNP did not influence the occurrence of T2DM (25), while other investigations reported that $\mathrm{G}$ allele of this SNP decreased the risk of T2DM $(26,27,28)$. Considering only four publications with moderate sample sizes exploring the correlation of rs2910164 with the occurrence of T2DM in Asians, the observations might be underpowered. In this study, 1284 participants were included to assess a correlation of rs2910164 in miR-146a gene with T2DM risk. We identified that rs2910164 in miR-146a gene decreased the risk of T2DM. In our study, a Bonferroni correction was harnessed to confirm our findings. After adjustment, the correlation of rs2910164 with the occurrence of T2DM also existed in overall comparison and in BMI $\geq 24 \mathrm{~kg} / \mathrm{m}^{2}$ and never drinking subgroups, which was similar to the findings of a more recent meta-analysis (30). In the future, more well-matched investigations are needed to confirm or refute our observations.

There are some limitations in our study. First, selective bias might exist. T2DM patients and normal controls came from two different hospitals, and these subjects could not well represent the Chinese populations. Secondly, only three miR-SNPs were included and studied in our study, more polymorphisms widely investigated should be included by artificial neural networks database. Thirdly, for temporary limitation of T2DM sample size and type, we couldn't perform genotype-based mRNA expression analysis. However, further investigations with detailed gene-environmental factors and functional exploring are certainly needed (53). Fourthly, in some subgroups, the sample size might be insufficient. Fifth, variant distribution of rs11614913 was suggested to be out of HWE in overall and some subgroups comparisons. The findings should be explained with caution. Finally, this study did not focus on the detailed information on T2DM complications, which might restrict a further evaluation of the mentioned SNPs on prognosis of T2DM.

In summary, this study highlights that miR-146a rs2910164 SNP is associated with decreases in susceptibility of T2DM, especially in BMI $\geq 24 \mathrm{~kg} / \mathrm{m}^{2}$ and non-smoking group. In addition, we also found that miR-196a2 rs11614913 C allele decreases the susceptibility of T2DM significantly in smoking subgroup.

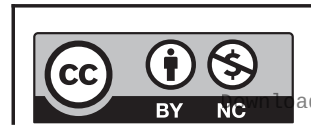




\section{Declaration of interest}

The authors declare that there is no conflict of interest that could be perceived as prejudicing the impartiality of the research reported.

\section{Funding}

The project was supported by the Joint Funds for the innovation of Science and Technology, Fujian province, China (grant numbers 2017Y9015); the Educational Commission of Yunnan Province, China (grant number 2017ZDX116)

\section{Acknowledgements}

The authors appreciate all subjects who participated in this study. We wish to thank Dr Yan Liu (Genesky Biotechnologies Inc., Shanghai, China) for technical support.

\section{References}

1 Xu Y, Wang L, He J, Bi Y, Li M, Wang T, Wang L, Jiang Y, Dai M, Lu J, et al. Prevalence and control of diabetes in Chinese adults. JAMA 2013 310 948-959. (https://doi.org/10.1001/jama.2013.168118)

2 Ramachandran A, Ma RC \& Snehalatha C. Diabetes in Asia. Lancet 2010375 408-418. (https://doi.org/10.1016/S0140-6736(09)60937-5)

3 Kwak SH \& Park KS. Recent progress in genetic and epigenetic research on type 2 diabetes. Experimental and Molecular Medicine 201648 e220. (https://doi.org/10.1038/emm.2016.7)

4 Sakurai M, Nakamura K, Miura K, Takamura T, Yoshita K, Nagasawa SY, Morikawa Y, Ishizaki M, Kido T, Naruse Y, et al. Dietary carbohydrate intake, presence of obesity and the incident risk of type 2 diabetes in Japanese men. Journal of Diabetes Investigation 20167 343-351. (https:// doi.org/10.1111/jdi.12433)

5 Xi L, Chow CM \& Kong X. Role of tissue and systemic hypoxia in obesity and Type 2 diabetes. Journal of Diabetes Research 20162016 1527852. (https://doi.org/10.1155/2016/1527852)

6 van Dijk SJ, Tellam RL, Morrison JL, Muhlhausler BS \& Molloy PL. Recent developments on the role of epigenetics in obesity and metabolic disease. Clinical Epigenetics 20157 66. (https://doi. org/10.1186/s13148-015-0101-5)

7 Panarelli NC \& Yantiss RK. MicroRNA expression in selected carcinomas of the gastrointestinal tract. Pathology Research International 20112011 124608. (https://doi.org/10.4061/2011/124608)

8 Noonan EJ, Place RF, Basak S, Pookot D \& Li LC. miR-449a causes Rb-dependent cell cycle arrest and senescence in prostate cancer cells. Oncotarget 20101 349-358. (https://doi.org/10.18632/oncotarget.167)

9 Vasudevan S, Tong Y \& Steitz JA. Switching from repression to activation: microRNAs can up-regulate translation. Science 2007318 1931-1934. (https://doi.org/10.1126/science.1149460)

10 Chang H, Chang H, Cheng T, Lee GD, Chen X \& Qi K. Microribonucleic acid-23a-3p prevents the onset of type 2 diabetes mellitus by suppressing the activation of nucleotide-binding oligomerizationlike receptor family pyrin domain containing 3 inflammatory bodies-caused pyroptosis through negatively regulating NIMA-related kinase 7. Journal of Diabetes Investigation 202112 334-345. (https://doi org/10.1111/jdi.13396)

11 He C, Zhang Q, Sun H, Cai R \& Pang W. Role of miRNA and lncRNA in animal fat deposition - a review. Sheng Wu Gong Cheng Xue Bao 2020 36 1504-1514. (https://doi.org/10.13345/j.cjb.200232)

12 Guo R, Yu Y, Zhang Y, Li Y, Chu X, Lu H \& Sun C. Overexpression of miR-297b-5p protects against stearic acid-induced pancreatic beta-cell apoptosis by targeting LATS2. American Journal of Physiology: Endocrinology and Metabolism 2020318 E430-E439. (https://doi. org/10.1152/ajpendo.00302.2019)
13 McDonald RA, Halliday CA, Miller AM, Diver LA, Dakin RS, Montgomery J, McBride MW, Kennedy S, McClure JD, Robertson KE, et al. Reducing in-stent restenosis: therapeutic manipulation of miRNA in vascular remodeling and inflammation. Journal of the American College of Cardiology 201565 2314-2327. (https://doi.org/10.1016/j. jacc.2015.03.549)

14 Afzal TA, Luong LA, Chen D, Zhang C, Yang F, Chen Q, An W, Wilkes E, Yashiro K, Cutillas PR, et al. NCK associated protein 1 modulated by miRNA-214 determines vascular smooth muscle cell migration, proliferation, and neointima hyperplasia. Journal of the American Heart Association 20165 e004629. (https://doi.org/10.1161/JAHA.116.004629)

15 Maves CK, Johnson JF, Bove K \& Malott RL. Gastric inflammatory pseudotumor in children. Radiology 1989173 381-383. (https://doi. org/10.1148/radiology.173.2.2678252)

16 Jin X, Chen D, Zheng RH, Zhang H, Chen YP \& Xiang Z. miRNA-133aUCP2 pathway regulates inflammatory bowel disease progress by influencing inflammation, oxidative stress and energy metabolism. World Journal of Gastroenterology 201723 76-86. (https://doi. org/10.3748/wjg.v23.i1.76)

17 Torella D, Iaconetti C, Tarallo R, Marino F, Giurato G, Veneziano C, Aquila I, Scalise M, Mancuso T, Cianflone E, et al. miRNA regulation of the hyperproliferative phenotype of vascular smooth muscle cells in diabetes. Diabetes 201867 2554-2568. (https://doi.org/10.2337/db171434)

18 Wang SS, Wang C \& Chen $\mathrm{H}$. MicroRNAs are critical in regulating smooth muscle cell mineralization and apoptosis during vascular calcification. Journal of Cellular and Molecular Medicine 202024 13564-13572. (https://doi.org/10.1111/jcmm.16005)

19 Sun Q, Gu H, Zeng Y, Xia Y, Wang Y, Jing Y, Yang L \& Wang B. Hsamir-27a genetic variant contributes to gastric cancer susceptibility through affecting miR-27a and target gene expression. Cancer Science 2010101 2241-2247. (https://doi.org/10.1111/j.13497006.2010.01667.x)

20 Lu D, Yao Q, Zhan C, Le-Meng Z, Liu H, Cai Y, Tu C, Li X, Zou Y $\&$ Zhang S. MicroRNA-146a promote cell migration and invasion in human colorectal cancer via carboxypeptidase $\mathrm{M} / \mathrm{src}-\mathrm{FAK}$ pathway. Oncotarget 20178 22674-22684. (https://doi.org/10.18632/ oncotarget.15158)

21 Mohamed RH, Pasha HF, Gad DM \& Toam MM. miR-146a and miR196a-2 genes polymorphisms and its circulating levels in lung cancer patients. Journal of Biochemistry 2019166 323-329. (https://doi. org/10.1093/jb/mvz044)

22 Jia Y, Zang A, Shang Y, Yang H, Song Z, Wang Z, Ren L, Wei Y, Hu L, Shi H, et al. MicroRNA-146a rs2910164 polymorphism is associated with susceptibility to non-small cell lung cancer in the Chinese population. Medical Oncology 201431 194. (https://doi.org/10.1007/ s12032-014-0194-2)

23 Jeon HS, Lee YH, Lee SY, Jang JA, Choi YY, Yoo SS, Lee WK, Choi JE, Son JW, Kang YM, et al. A common polymorphism in pre-microRNA$146 \mathrm{a}$ is associated with lung cancer risk in a Korean population. Gene 2014534 66-71. (https://doi.org/10.1016/j.gene.2013.10.014)

24 Liu XS, Fan B, Szalad A, Jia L, Wang L, Wang X, Pan W, Zhang L, Zhang R, Hu J, et al. MicroRNA-146a mimics reduce the peripheral neuropathy in Type 2 diabetic mice. Diabetes 201766 3111-3121. (https://doi.org/10.2337/db16-1182)

25 Wang TT, Chen YJ, Sun LL, Zhang SJ, Zhou ZY \& Qiao H. Affection of single-nucleotide polymorphisms in miR-27a, miR-124a, and miR-146a on susceptibility to type 2 diabetes mellitus in Chinese Han people. Chinese Medical Journal 2015128 533-539. (https://doi. org/10.4103/0366-6999.151112)

26 Li Y, Zhang Y, Li X, Shi L, Tao W, Shi L, Yang M, Wang X, Yang Y \& Yao Y. Association study of polymorphisms in miRNAs with T2DM in Chinese population. International Journal of Medical Sciences 201512 875-880. (https://doi.org/10.7150/ijms.12954)

27 Alipoor B, Meshkani R, Ghaedi H, Sharifi Z, Panahi G \& Golmohammadi T. Association of miR-146a rs2910164 and miR-149 https://ec.bioscientifica.com https://doi.org/10.1530/EC-21-0261 (c) 2021 The authors Published by Bioscientifica Ltd
This work is licensed under a Creative Commons Attribution-NonCommercial 4.0 International License. ded from Bioscientifica.com at 04/26/2023 01:20:06PM 
rs2292832 variants with susceptibility to Type 2 diabetes. Clinical Laboratory 201662 1553-1561. (https://doi.org/10.7754/Clin. Lab.2016.160124)

28 Ciccacci C, Di Fusco D, Cacciotti L, Morganti R, D’Amato C, Greco C, Rufini S, Novelli G, Sangiuolo F, Spallone V, et al. MicroRNA genetic variations: association with type 2 diabetes. Acta Diabetologica 201350 867-872. (https://doi.org/10.1007/s00592-013-0469-7)

29 Cheng L, Zhou M, Zhang D \& Chen B. Association of miR-146a polymorphism rs2910164 and type 2 diabetes risk: a meta-analysis. Journal of International Medical Research 202048300060520931313. (https://doi.org/10.1177/0300060520931313)

30 Gholami M, Asgarbeik S, Razi F, Esfahani EN, Zoughi M, Vahidi A, Larijani B \& Amoli MM. Association of microRNA gene polymorphisms with type 2 diabetes mellitus: a systematic review and meta-analysis. Journal of Research in Medical Sciences 20202556. (https://doi.org/10.4103/jrms.JRMS_751_19)

31 Yao M, Wu Y, Fang Q, Sun L, Li T \& Qiao H. Association of ADIPOQ variants with type 2 diabetes mellitus susceptibility in ethnic Han Chinese from northeast China. Journal of Diabetes Investigation 20167 853-859. (https://doi.org/10.1111/jdi.12535)

32 Fan Y, Li X, Zhang Y, Fan X, Zhang N, Zheng H, Song Y, Shen C, Shen J Ren F, et al. Genetic variants of TPCN2 associated with Type 2 diabetes risk in the Chinese population. PLoS ONE 201611 e0149614. (https:// doi.org/10.1371/journal.pone.0149614)

33 Zhai Y, Zhao WH \& Chen CM. Verification on the cut-offs of waist circumference for defining central obesity in Chinese elderly and tall adults. Zhonghua Liu Xing Bing Xue Za Zhi 201031 621-625. (https:// doi.org/10.3760/cma.j.issn.0254-6450.2010.06.005)

34 Zhang X, Zhang S, Li Y, Detrano RC, Chen K, Li X, Zhao L, Benjamin EJ $\&$ Wu Y. Association of obesity and atrial fibrillation among middleaged and elderly Chinese. International Journal of Obesity 200933 1318-1325. (https://doi.org/10.1038/ijo.2009.157)

35 Chen C, Hong H, Chen L, Shi X, Chen Y \& Weng Q. Association of microRNA polymorphisms with the risk of myocardial infarction in a Chinese population. Tohoku Journal of Experimental Medicine 2014233 89-94. (https://doi.org/10.1620/tjem.233.89)

36 Huang S, Lv Z, Deng Q, Li L, Yang B, Feng J, Wu T, Zhang X \& Cheng J. A genetic variant in pre-miR-146a (rs2910164 C $>\mathrm{G}$ ) is associated with the decreased risk of acute coronary syndrome in a Chinese population. Tohoku Journal of Experimental Medicine 2015237 227-233. (https://doi.org/10.1620/tjem.237.227)

37 Chen S, Cao R, Liu C, Tang W \& Kang M. Investigation of IL-4, IL-10, and HVEM polymorphisms with esophageal squamous cell carcinoma: a case-control study involving 1929 participants. Bioscience Reports 202040 BSR20193895. (https://doi.org/10.1042/BSR20193895)

38 Chen Z, Wang Y, Wang J, Kang M, Tang W \& Chen S. Assessment of PPARGC1A, PPARGC1B, and PON1 genetic polymorphisms in esophageal squamous cell carcinoma susceptibility in the Eastern Chinese Han population: a case-control study involving 2351 subjects. DNA and Cell Biology 202039 1521-1531. (https://doi.org/10.1089/ dna.2020.5416)

39 Zhang S, Chen L, Wang Y, Tang W, Chen Y \& Liu L. Investigation of the association of miRNA-499, miRNA-146a, miRNA-196a2 loci with hepatocellular carcinoma risk: a case-control study involving 1507 subjects. DNA and Cell Biology 202039 379-388. (https://doi. org/10.1089/dna.2019.5145)

40 Tang W, Liu J, Zhong Z, Qiu H \& Kang M. Association of metabolismrelated genes polymorphisms with adenocarcinoma of the oesophagogastric junction: evidence from 2261 subjects. Journal of
Cellular Biochemistry 2019120 18689-18701. (https://doi.org/10.1002/ jcb.29167)

41 Tang W, Chen S, Liu J, Liu C, Wang Y \& Kang M. Investigation of IGF1, IGF2BP2, and IGFBP3 variants with lymph node status and esophagogastric junction adenocarcinoma risk. Journal of Cellular Biochemistry 2019120 5510-5518. (https://doi.org/10.1002/jcb.27834)

42 Bland JM \& Altman DG. Multiple significance tests: the Bonferroni method. BMJ 1995310 170. (https://doi.org/10.1136/ bmj.310.6973.170)

43 Lesack K \& Naugler C. An open-source software program for performing Bonferroni and related corrections for multiple comparisons. Journal of Pathology Informatics 20112 52. (https://doi. org/10.4103/2153-3539.91130)

44 Purvis GSD, Collino M, Loiola RA, Baragetti A, Chiazza F, Brovelli M, Sheikh MH, Collotta D, Cento A, Mastrocola R, et al. Identification of annexinA1 as an endogenous regulator of RhoA, and its role in the pathophysiology and experimental therapy of Type-2 diabetes. Frontiers in Immunology 201910 571. (https://doi.org/10.3389/ fimmu.2019.00571)

45 Marshall SA, Qin CX, Jelinic M, O'Sullivan K, Deo M, Walsh J, Li M, Parry LJ, Ritchie RH \& Leo CH. The novel small-molecule annexin-A1 mimetic, compound $17 \mathrm{~b}$, elicits vasoprotective actions in streptozotocin-induced diabetic mice. International Journal of Molecular Sciences 202021 1384. (https://doi.org/10.3390/ijms21041384)

46 Huang JJ, Xia CJ, Wei Y, Yao Y, Dong MW, Lin KZ, Yu LS, Gao Y \& Fan YY. Annexin A1-derived peptide Ac2-26 facilitates wound healing in diabetic mice. Wound Repair and Regeneration 202028 772-779. (https://doi.org/10.1111/wrr.12860)

47 Luthra R, Singh RR, Luthra MG, Li YX, Hannah C, Romans AM, Barkoh BA, Chen SS, Ensor J, Maru DM, et al. MicroRNA-196a targets annexin A1: a microRNA-mediated mechanism of annexin A1 downregulation in cancers. Oncogene 200827 6667-6678. (https://doi. org/10.1038/onc.2008.256)

48 Landgraf P, Rusu M, Sheridan R, Sewer A, Iovino N, Aravin A, Pfeffer S, Rice A, Kamphorst AO, Landthaler M, et al. A mammalian microRNA expression atlas based on small RNA library sequencing. Cell 2007129 1401-1414. (https://doi.org/10.1016/j.cell.2007.04.040)

49 Yin Z, Cui Z, Ren Y, Xia L, Li H \& Zhou B. MiR-196a2 and lung cancer in Chinese non-smoking females: a genetic association study and expression analysis. Oncotarget 20178 70890-70898. (https://doi. org/10.18632/oncotarget.20174)

50 Zhao H, Xu J, Zhao D, Geng M, Ge H, Fu L \& Zhu Z. Somatic mutation of the SNP rs11614913 and its association with increased MIR 196A2 expression in breast cancer. DNA and Cell Biology 201635 81-87. (https://doi.org/10.1089/dna.2014.2785)

51 Ghanbari M, Sedaghat S, de Looper HW, Hofman A, Erkeland SJ, Franco OH \& Dehghan A. The association of common polymorphisms in miR-196a2 with waist to hip ratio and miR-1908 with serum lipid and glucose. Obesity 201523 495-503. (https://doi.org/10.1002/ oby.20975)

52 Yin Z, Cui Z, Guan P, Li X, Wu W, Ren Y, He Q \& Zhou B. Interaction between polymorphisms in pre-MiRNA genes and cooking oil fume exposure on the risk of lung cancer in Chinese non-smoking female population. PLOS ONE 201510 e0128572. (https://doi.org/10.1371/ journal.pone.0128572)

53 Zhuo ZJ, Liu W, Zhang J, Zhu J, Zhang R, Tang J, Yang T, Zou Y, He J \& Xia H. Functional polymorphisms at ERCC1/XPF genes confer neuroblastoma risk in Chinese children. EBiomedicine 201830 113-119. (https://doi.org/10.1016/j.ebiom.2018.03.003)

Received in final form 30 August 2021

Accepted 30 September 2021

Accepted Manuscript published online 1 October 2021 https://ec.bioscientifica.com https://doi.org/10.1530/EC-21-0261 (c) 2021 The authors Published by Bioscientifica Ltd

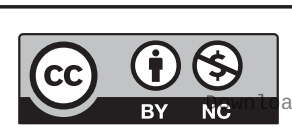

This work is licensed under a Creative Commons Attribution-NonCommercial 4.0 International License. ded from Bioscientifica.com at 04/26/2023 01:20:06PM 